\title{
Biochemical abnormalities in OPC poisoning and its prognostic significance
}

\author{
"Dr.N.K.SenthilnathanMD, ${ }^{2}$ Dr.L.Alen Binny MD \\ ${ }^{1}$ Professor, Department Of Medicine, KAPV Government Medical College, Tiruchirapalli \\ ${ }^{2}$ Resident, Department Of Medicine, KAPV Government Medical College, Tiruchirapalli \\ Corresponding author: *Dr.L.Alen Binny
}

\begin{abstract}
Organophosphorus insecticides are arguably one of the commonest causes of morbidity and mortality due to poisoning worldwide, especially in developing countries like India due to its easy availability. Though Serum cholinesterase can be a useful tool in the diagnosis of OP poisoning, its role in prognostication is very minimal. The aim of the study is to measure serum electrolytes, liver enzymes, amylase, CPK, CPK-MB, and Troponin I in acute organophosphorus poisoning, to analyse the correlation between these biochemical parameters and serum acetylcholinesterase levels and to assess the validity of these biochemical parameters in prediction of severity and prognosis in op poisoning. This study was conducted over a period of 1 year in Mahatma Gandhi Memorial Government Hospital attached to K.A.P.V Govt Medical College, Trichy. Statistically significant elevation of ALT, AST, Amylase, CPK, CPK-MB and Troponin I were noted in the study group. A significant fall in serum potassium level in also noted. Rise in CPK, CPK-MB, Troponin I and ALT indicate the severity of OP poisoning and is also statistically significant to predict the prognosis of the patient. Hypokalaemia and associated low cholinesterase levels indicate the requirement of ventilator support.
\end{abstract}

Keywords: Organophosphate (OP) poisoning, Aspartate transaminase, Alanine transaminase (ALT), Creatine phosphokinase (CPK, CPK-MB), Amylase, Troponin I, Serum Cholinesterase (S.AchE), Potassium.

\section{Introduction}

Pesticides are a class of toxic substances that are intentionally released into the environment for the greater good it does that exceeds their toxicological concerns. Pesticide poisoning is a major health hazard in the developing world. The exact rate of OP poisoning in India is not clear because of under reporting and lack of data. In many reports from India, rate of suicidal poisoning with Opc ranges from 10 to $43 \%$. The morbidity and mortality in these patients depends on the time lag between the exposure and the onset of management. So it is very important to recognise the whole spectrum of symptoms in OP poisoning. The need for newer biomarkers in relation to OP poisoning started a very long time ago. In a limited resourced country like India, we need cheap and easily measurable biomarkers. Many studies were conducted regarding this and were shown that Serum cholinesterase can be a useful tool in the diagnosis of OP poisoning. But its role in prognostication is very minimal. Our study was conducted to assess parameters like CPK-MB, Serum potassium, Troponin I in correlation with Serum cholinesterase along with other liver enzymes, and serum amylase to predict the severity and prognosis in OP poisoning patients.

\section{Aims and objectives}

1. To measure serum acetylcholinesterase, serum electrolytes, liver enzymes, amylase, cpk, cpk-mb, and troponin I, in acute organophosphorus poisoning

2. To analyse the correlation between these biochemical parameters and serum acetylcholinesterase levels

3. To analyse the validity of these biochemical parameters in prediction of severity and prognosis in op poisoning

Source of Data:

\section{Materials And Methods}

The present Study was done at Mahatma Gandhi Memorial Govt. Hospital attached with K.A.P.V. Govt. Medical College, Tiruchirappalli.

Study Design:

Cross-sectional prospective Study

Period of Study

The study, was conducted from June 2015 to June 2016.

Inclusion Criteria 
All the OP poisoning cases confirmed by history, circumstantial evidence of ingestion, admitted in our hospital within 12 hours of ingestion with characteristic clinical findings and basic laboratory investigations were included in the study

\section{Exclusion Criteria}

- Patients with feature of exposure to another compound not relating to OP Poison.

- Patients with mixed poisoning; OP poisoning and any other poison

- Patients who has chronic alcoholism

- Patients with history suggestive of liver disease

- History suggestive of myopathy

- Patients with history of malignancy and autoimmune diseases

- Patients with history of renal disease

- Patients with history of cardiac disease

\section{Statistical Analysis}

All the parameters were tabulated. Mean, Standard deviation were analysed using SPSS 20 software. All the biochemical parameters were correlated with serum cholinesterase using intercorrelations. Chi-square test was the test of significance used for qualitative variables to find the association between them. T test was the test of significance used for comparing quantitative variables with qualitative variable. One-way Anova is used as test of significance to assess various parameters with the compound used for poisoning.

\section{Results}

Table 1 Descriptive Statistics Liver Enzymes, Amylase

\begin{tabular}{|l|l|l|l|l|l|}
\hline & N & Min. & Max & Mean & S.D \\
\hline Ast & 50 & 20 & 220 & 113.48 & 50.287 \\
\hline Alt & 50 & 18 & 220 & 109.62 & 50.004 \\
\hline Alp & 50 & 48 & 362 & 165.96 & 82.646 \\
\hline Amylase & 50 & 34 & 360 & 160.96 & 93.453 \\
\hline
\end{tabular}

Table 2 Descriptive Statistics Serum Electrolytes

\begin{tabular}{|l|l|l|l|l|}
\hline & Min. & Max & Mean & S.D \\
\hline $\begin{array}{l}\text { Sodium } \\
\text { In Meq/L) }\end{array}$ & 126 & 144 & 134.90 & 3.370 \\
\hline $\begin{array}{l}\text { Potassium } \\
\text { (In Meq/L) }\end{array}$ & 2.60 & 3.80 & 3.2140 & .22769 \\
\hline
\end{tabular}

Table 3 Descriptive Statistics Cpk, Cpk Mb

\begin{tabular}{|l|l|l|l|l|}
\hline & Min. & Max & Mean & S.D \\
\hline $\begin{array}{l}\text { Cpk } \\
(\mathrm{Iu} / \mathrm{L})\end{array}$ & 30 & 3738 & 802.38 & 955.396 \\
\hline $\begin{array}{l}\text { Cpk-Mb } \\
(\mathrm{Iu} / \mathrm{L})\end{array}$ & 15 & 758 & 191.76 & 207.497 \\
\hline
\end{tabular}

Table 4 Compare The Outcome With Troponin I

\begin{tabular}{|c|c|c|c|c|c|c|c|}
\hline \multirow{2}{*}{ Trop I } & \multicolumn{2}{|l|}{ Death } & \multicolumn{2}{|l|}{ Live } & \multicolumn{2}{|l|}{ Total } & \multirow{2}{*}{$\begin{array}{l}\text { Statistical } \\
\text { inference }\end{array}$} \\
\hline & $(\mathrm{N}=21)$ & $(100 \%)$ & $(\mathrm{N}=29)$ & $(100 \%)$ & $(\mathrm{N}=50)$ & $(100 \%)$ & \\
\hline Negative & 0 & $.0 \%$ & 27 & $93.1 \%$ & 27 & $54.0 \%$ & $X^{2}=42.504$ \\
\hline Positive & 21 & $100.0 \%$ & 2 & $6.9 \%$ & 23 & $46.0 \%$ & $\begin{array}{l}\mathrm{Df}=1 \\
.000<0.05 \\
\text { Significant }\end{array}$ \\
\hline
\end{tabular}

Table 5 Enzymes With Outcome

\begin{tabular}{|c|c|c|c|}
\hline Ast & Mean & S.D & Statistical Inference \\
\hline Live $(\mathrm{N}=29)$ & 102.24 & 50.026 & \multirow{2}{*}{$\begin{array}{l}\mathrm{T}=-1.906 \mathrm{Df}=48 \\
.063>0.05 \\
\text { Not Significant }\end{array}$} \\
\hline Death $(\mathrm{N}=21)$ & 129.00 & 47.494 & \\
\hline Alt & Mean & S.D & Statistical Inference \\
\hline Live (N=29) & 93.31 & 50.985 & \multirow{2}{*}{$\begin{array}{l}\mathrm{T}=-2.909 \mathrm{Df}=48 \\
.005<0.05 \\
\text { Significant }\end{array}$} \\
\hline Death $(\mathrm{N}=21)$ & 132.14 & 39.603 & \\
\hline Alp & Mean & S.D & Statistical Inference \\
\hline Live $(\mathrm{N}=29)$ & 157.90 & 76.705 & \multirow{2}{*}{$\begin{array}{l}\mathrm{T}=-.808 \mathrm{Df}=48 \\
.423>0.05 \\
\text { Not Significant }\end{array}$} \\
\hline Death $(\mathrm{N}=21)$ & 177.10 & 90.954 & \\
\hline
\end{tabular}


Biochemical Abnormalities In Opc Poisoning And Its Prognostic Significance

\begin{tabular}{|l|l|l|l|}
\hline & & & \\
\hline Amylase & Mean & S.D & Statistical Inference \\
\hline Live $(\mathrm{N}=29)$ & 140.59 & 84.798 & $\begin{array}{l}\text { T=-1.856 Df }=48 \\
.070>0.05 \\
\text { Not Significant }\end{array}$ \\
\cline { 1 - 2 } Death $(\mathrm{N}=21)$ & 189.10 & 99.484 & \\
\hline
\end{tabular}

Table 6 Electrolytes With Outcome

\begin{tabular}{|c|c|c|c|}
\hline Sodium & Mean & S.D & Statistical Inference \\
\hline Live $(\mathrm{N}=29)$ & 135.41 & 3.123 & \multirow{2}{*}{$\begin{array}{l}\mathrm{T}=1.275 \mathrm{Df}=48 \\
.208>0.05 \\
\text { Not Significant }\end{array}$} \\
\hline Death $(\mathrm{N}=21)$ & 134.19 & 3.642 & \\
\hline Potassium & Mean & S.D & Statistical Inference \\
\hline Live $(\mathrm{N}=29)$ & 3.2690 & .23468 & \multirow{2}{*}{$\begin{array}{l}\mathrm{T}=2.072 \mathrm{Df}=48 \\
.044<0.05 \\
\text { Significant }\end{array}$} \\
\hline Death $(\mathrm{N}=21)$ & 3.1381 & .19869 & \\
\hline
\end{tabular}

Table 7 SchE with outcome

\begin{tabular}{|l|l|l|l|}
\hline S.Ache & Mean & S.D & Statistical Inference \\
\hline Live $(\mathrm{N}=29)$ & 2357.34 & 2242.477 & $\begin{array}{l}\mathrm{T}=3.096 \mathrm{Df}=48 \\
.003<0.05 \\
\text { Significant }\end{array}$ \\
\cline { 1 - 3 }$(\mathrm{N}=21)$ & 821.00 & 399.836 & $\underline{2}$ \\
\hline
\end{tabular}

Table 8 CPK \& CPK MB with outcome

\begin{tabular}{|c|c|c|c|}
\hline CPK & Mean & S.D & Statistical inference \\
\hline Live $(n=29)$ & 444.76 & 621.248 & \multirow{2}{*}{$\begin{array}{l}\mathrm{T}=-3.436 \mathrm{Df}=48 \\
.001<0.05 \\
\text { Significant }\end{array}$} \\
\hline Death $(n=21)$ & 1296.24 & 1120.022 & \\
\hline CPK-MB & Mean & S.D & Statistical inference \\
\hline Live $(n=29)$ & 81.72 & 93.538 & \multirow{2}{*}{$\begin{array}{l}\mathrm{T}=-5.613 \mathrm{Df}=48 \\
.000<0.05 \\
\text { Sionificant }\end{array}$} \\
\hline Death $(n=21)$ & 343.71 & 226.792 & \\
\hline
\end{tabular}

\section{Discussion}

Organophosphate ingestion is one of the supreme cause of suicidal deaths in India. Inhibition of acetylcholinesterase is the main mechanism by which organophosphates act leading to excessive cholinergic stimulation. The clinical features of cholinergic storm develops fast, which helps in diagnosing clinically that is established by detailed history and biochemical demonstration of cholinesterase inhibition. This study is undertaken to analyse the biochemical abnormalities in organophosphate poisoning and to assess their prognostic significance.In this study the total number of patients were 50. Among them 37 of them were male $(74 \%)$ and 13 of them were female $(26 \%)$, showing that the incidence of poisoning is more in males. The mean values of AST-113.48 IU/L, ALT-109.62 IU/L, ALP- 165.96 IU/L, and Amylase- 160.96 IU/L is noted among the poisoning patients in this study. According to Lohitnavy \& Vijayaraghavan ${ }^{(1,2)}$, there is elevation of Serum AST and ALT because of degeneration of hepatocytes and further necrosis, causing damage to cell organelles like mitochondria and pouring these enzymes into blood stream ${ }^{(3,4)}$. The present study also demonstrates elevation in liver enzymes following OP poisoning (Table 1). Among the liver enzymes ALT elevation shows a statistical significance when compared with the outcome and thus can be used as a prognostic indicator (Table 5). Singh et $\mathrm{al}^{(5)}$ found elevation of amylase and acute pancreatitis in OP poisoning. Matsumiya $\mathrm{N}$ et al ${ }^{(6)}$ and $\mathrm{Li}$ $\mathrm{T}$ Nagayama $\mathrm{N}$ et $\mathrm{al}^{(7)}$ stated that elevated serum amylase in the absence of clinical pancreatitis could be attributed to hypoxemia. Dressel et al $^{(8)}$ showed that OP intoxication causes increase in intraductal pressure and increase in exocrine pancreas flow rate resulting in extravasation of fluid. The mean serum potassium in our study is $3.2 \mathrm{meq} / \mathrm{l}$ (Table 2). According to Devanur RMM and Prasad et al ${ }^{(9)}$, poor outcome in OP poisoning was noted in patients having respiratory distress with hypokalaemia and very low serum cholinesterase. They also found that there was a remarkable fall in serum potassium relating to OP toxicity induced weakness of muscle and paralysis finally leading to death. The fall in serum potassium was proportional to the onset of detrimental signs and symptoms. In our study the mean potassium in patients with successful outcome is 3.2 and in patients who had a negative endpoint is 3.13. The p value for statistical significance is $<0.05$ (Table 6). The mean CPK in our study is $802.38 \mathrm{IU} / \mathrm{L}$ and CPK MB is $191.76 \mathrm{IU} / \mathrm{L}$ (Table 8). In a study conducted in Egypt by Nermeen $\mathrm{AM}$ et al ${ }^{(10)}$ they have demonstrated increases in serum CPK and a proportionate fall in serum cholinesterase. The excess of acetylcholine in OP poisoning causes reversible muscle injury and rise in various muscle enzymes including $\mathrm{CPK}^{(11)}$. Dayanand Raddi et al conducted a study regarding $\mathrm{CPK}$ and OP poisoning and concluded escalation of CPK is evident of respiratory-failure and timely estimation of CPK has to be customarily taken as 
a prognostic indicator in OP poisoning ${ }^{(12)}$. The mechanism behind cardio toxicity of Organophosphates is not known. It is postulated that parasympathetic and sympathetic over activity causes myocardial damage. Parasympathetic over activity has significant role in coronary artery spasm. In our study also there is a significant correlation between CPK, CPK MB (Table 8), and Troponin I (Table 4) and the outcome of patient. Hence these three parameters can be used as a prognostic indicator in OP poisoning. In our study serum cholinesterase mean value in patients who had successful outcome is $2357 \mathrm{IU} / \mathrm{L}$ and it is $821 \mathrm{IU} / \mathrm{L}$ in those who had a negative outcome. In our study the serum cholinesterase measured on the day of admission predicts the outcome with high statistical significance (Table 7).

\section{Conclusion}

1. Incidence is high in male patients

2. Measurement of Serum potassium and serum cholinesterase is helpful in predicting the outcome and prognosis in OP poisoning. Hypokalaemia associated with reduced cholinesterase level is related with a negative outcome.

3. Increase in serum creatinekinase is commonly seen in organophosphate poisoning.

4. Increase in CPK MB and Troponin I is commonly seen in organophosphate poisoning because of the cardio toxicity involved in OP poisoning

5. CPK, CPK MB and Troponin I have high statistical significance

6. Prognosis of the patient.

7. The significant increase of liver enzyme activity and serum amylase appears to correlate with clinical severity of the patient in OP poisoning.

8. Among the liver enzymes and serum amylase, ALT elevation has a statistical significance to predict the outcome of the patient.

\section{Limitations}

1. The period of study is minimal, huge data would have been collected if done for long time.

2. Study group is just adequate.

3. Serial estimation of the biochemical parameters during the course of hospital stay is not done.

4. Troponin I is done in qualitative method and not quantitative method.

5. Previously undiagnosed cardiac disease is not ruled out in the study patients.

\section{Bibliography}

[1]. Lohitnavy O, Sinhaseni P. Increase in lactate dehydrogenase isoenzyme-4 and splenocyte toxicity in methomyl-treated rats. Arhivzahigijenuradaitoksikologiju. 1999;49(3):231-8

[2]. Vijayaraghavan M, Nagarajan B. Mutagenic potential of acute exposure to organophosphorus and organochlorine compounds. Mutation Research/Genetic Toxicology. 1994;321(1):103-11.

[3]. Anormallikleri L. Emergency laboratory abnormalities in suicidal patients with acute organophosphate poisoning. TürkBiyokimyaDergisi [Turkish Journal of Biochemistry-Turk J Biochem]. 2010;35(1):29-34.

[4]. Clark RF. Insecticides: organic phosphorus compounds and carbamates. Goldfrank'stoxicologic emergencies. 2002;8:1497-512.

[5]. Singh S, Bhardwaj U, Bhalla A, Gill K. Hyperamylasemia and acute pancreatitis following anticholinesterase poisoning. Human \& experimental toxicology. 2007;26(6):467-71.

[6]. Matsumiya N, Tanaka M, Iwai M, Kondo T, Takahashi S, Sato S. Elevated amylase is related to the development of respiratory failure in organophosphate poisoning. Human \& experimental toxicology. 1996;15(3):250-3.

[7]. Li T, Nagayama N, Kawabe Y, Ohtsuka Y, Machida K, Haga T. [Hyperamylasemia in acute exacerbation in patients with chronic respiratory failure]. Nihon KyobuShikkanGakkaizasshi. 1989;27(4):488-96

[8]. Dressel T, GoodaleJr R, Arneson M, Borner J. Pancreatitis as a complication of anticholinesterase insecticide intoxication. Annals of surgery. 1979;189(2):199.

[9]. Prasad DR. Reduced Levels of Serum Potassium and Plasma Cholinesterase in Acute Organophosphate Poisoning: Possible Predictive Markers. Asia Pacific Journal of Medical Toxicology. 2014;3(2):68-72.

[10]. Nermeen A, Hassan MA. Correlation between serum creatine phosphokinase and severity of acute organophosphorus poisoning: A prospective clinical study (2012-2013). J Environ SciTox Food Technol. 2013;4:18-29.

[11]. John M, Oommen A, Zachariah A. Muscle injury in organophosphorous poisoning and its role in the development of intermediate syndrome. Neurotoxicology. 2003;24(1):43-53.

[12]. Raddi D, Anikethana G. Creatine Kinase for Prognostication in Organophosphorus Poisoning.

"Dr.L.Alen Binny MD. "Biochemical abnormalities in OPC poisoning and its prognostic significance." IOSR Journal of Dental and Medical Sciences (IOSR-JDMS) 16.7 (2017): 116-19. 